\title{
Article
}

\section{The Impact of Immersive Outdoor Activities in Local Woodlands on Young Carers Emotional Literacy and Well-Being}

\author{
Acton, J and Carter, Bernie \\ Available at http://clok.uclan.ac.uk/24702/ \\ Acton, J and Carter, Bernie ORCID: 0000-0001-5226-9878 (2016) The Impact \\ of Immersive Outdoor Activities in Local Woodlands on Young Carers \\ Emotional Literacy and Well-Being. Comprehensive Child and Adolescent \\ Nursing, 39 (2). pp. 94-106. ISSN 2469-4193
}

It is advisable to refer to the publisher's version if you intend to cite from the work. http://dx.doi.org/10.3109/01460862.2015.1115156

For more information about UCLan's research in this area go to http://www.uclan.ac.uk/researchgroups/ and search for < name of research Group>.

For information about Research generally at UCLan please go to http://www.uclan.ac.uk/research/

All outputs in CLoK are protected by Intellectual Property Rights law, including Copyright law. Copyright, IPR and Moral Rights for the works on this site are retained by the individual authors and/or other copyright owners. Terms and conditions for use of this material are defined in the policies page.

\section{CLoK}

Central Lancashire online Knowledge www.clok.uclan.ac.uk

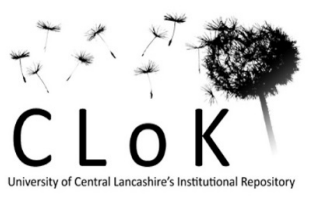




\title{
The impact of immersive outdoor activities in local woodlands on young carers emotional literacy and wellbeing.
}

\author{
Jane Acton, Bernie Carter
}

\section{Issues in Comprehensive Pediatric Nursing}

\begin{abstract}
Children's well-being is linked to a complex web of factors including the child's personality, inherent protective mechanisms, family relationships, social capital and economic status. Young carers are particularly at risk from poor mental health outcomes and low well-being. In this study the impact of immersive activities in nature on the well-being of eight young carers (three girls and five boys; aged 9-13 years) was explored. The immersive woodland activities included practical skills such as fire making, cooking and using tools as well as team building and activities to hep build trust. A mixed method, pre-test/post-test approach was undertaken using Emotional Literacy Checklists and interviews, poems and discussion. There were measurable improvements - specifically in motivation and self-awareness - in the young carers' emotional literacy as reported by the parents and teachers. The well-being indicators that were referenced most frequently by parents and teachers related to the children's social relationships and their development as individuals. The children reported changed related to social, physical and 'natural connection' well-being.
\end{abstract}




\section{Introduction}

Children's well-being is linked to a complex web of factors including the child's personality, inherent protective mechanisms, family relationships, social capital and economic status (The Children's Society, 2014). The subjective well being of children in the UK is reported as being less good than that of their peers in other countries (UNICEF, 2007; Bradshaw \& Richardson, 2009). Although these international variations are not well understood it is clear that children who are marginalised or under particular stress are at risk from experiencing poorer well-being than their peers (Doutre, Green \& Knight-Elliott, 2013). Children who are acting as carers are one such group whose well being is at risk and studies show that young carers report feeling anxious and depressed (Bjorgvinsdottir \& Halldorsdottir, 2014) and in need of support to ensure their emotional well being (McAndrew, Warne, Falon \& Moran, 2012).

Promoting children's emotional literacy can be a protective factor in relation to positive mental health as well as having other wider impacts such as increasing social capital (Weare \& Gray, 2003). Emotional literacy (EL) and emotional intelligence (EI) are closely related constructs (Sutton et al., 2005). EL is used in reference to a person's ability to express their emotions in a constructive way and empathise with others (Steiner, 1997; Steiner \& Perry, 1997). EI is gaining attention within the UK as a concept to support children's well being. Goleman (1996) proposes that EI is composed of five key parameters - self awareness, self regulation, self motivation, empathy, and social competence (see Table 1) - and argues that EI more important than intelligence quotient for success in life.

Table 1: Five key parameters of Emotional Intelligence (Goleman 1996)

\begin{tabular}{|l|l|}
\hline Self awareness & $\begin{array}{l}\text { by recognizing our feelings and emotions as they occur is which is } \\
\text { described as the most important; }\end{array}$ \\
\hline Self regulation & $\begin{array}{l}\text { by managing our emotions and handling feelings in a way which is } \\
\text { proportionate and appropriate; }\end{array}$ \\
\hline Self motivation & $\begin{array}{l}\text { by maintaining attention, focus and allowing for creativity to allow for } \\
\text { achievement of goals; }\end{array}$ \\
\hline Empathy & $\begin{array}{l}\text { by recognising how others are feeling and understanding their emotions. } \\
\text { This is thought to be a key skill. }\end{array}$ \\
\hline Social competence & $\begin{array}{l}\text { by managing relationships, influencing others, communicating well, } \\
\text { managing conflict and working collaboratively. }\end{array}$ \\
\hline
\end{tabular}


Whilst there are many different ways of trying to improve children's well being one currently receiving attention is engagement with nature and the outdoors. In many of the reports on children's well being the importance of play, sport (The Children's Society 2014) and participation in outdoor activities is identified. Children in the UK, Sweden and Spain report that their well-being centres having a happy stable family, good friends and 'plenty of things to do especially outdoors' (Ipsos MORI /UNICEF, 2011, p1). The benefits of 'green exercise' (Pretty et al., 2007), outdoor play (Fjortoft, 2004), children's preferences for wild spaces to play in (Elsley, 2004) present the health benefits that can accrue from being in contact with nature (Hewes \& MacEwan, 2005; Korpela, Hartig, Kaiser \& Fuhrer, 2001). Louv’s (2010) overview builds on Kaplan’s (1995) premise that the natural world can have a restorative impact which helps children cope with modern life, supports adaptive processes of child development, supports learning and the development of lifelong positive attitudes to the natural world. Gill's (2014) systematic review showed access to the natural world had positive effects specifically on child mental and emotional health.

This paper reports on an initiative undertaken by a social enterprise - Nature Workshops working with children and families from a young carers project to promote well-being and emotional literacy. The main focus of this paper is the presentation of the qualitative component.

\section{Methods}

This mixed methods study using quantitative methods (Emotional Literacy Checklists) and qualitative methods (interviews, poems and discussions) aimed to examine the affects of immersive outdoor activities in local woodlands on young carers emotional literacy and well-being. The delivery and research team was composed of four staff members from Nature Workshops: a researcher ethnobotanist, a Forest School Session Leader and bushcraft expert, and two Assistant Session Leaders with appropriate with youth work and special needs experience. Ethics approval was provided by the Plymouth University Ethics Committee; all stakeholders were given information about the study before they consented to participate. 


\section{Participants}

The participants of this study included young carers, their parents and their teachers. The young carers were pupils in mainstream school whose lives are dominated by caring for the needs of a parent. The young people self selected to engage in the project through their contact with a local charity for young carers.

\section{The intervention}

The intervention (a total of 24 hours over 5 days) was based on an immersive iterative model of outdoor activities in local woodlands during August 2012.

The outdoor activities were prepared iteratively according to the needs of the participants. Each session always included practical skills such as fire making, cooking and using tools to make simple artefacts and build shelters. The second and subsequent sessions each started by reflecting on what had been done previously and what impact the young people felt it had on them or their environment.

Team games (e.g., team hide and seek) and games for individuals were always played at each session, using all the space and spaces in the understorey (the layer of vegetation beneath the main canopy of the forest). Games also involved working in pairs with one young person who guides a blindfolded peer to 'meet a tree' who is asked to use their remaining senses to find out what they can about it before being led away from the tree and then asked to identify 'their' tree.

Each session also included time focussing on aspects of ecology such as using handheld microscopes to look at the micro fauna and flora or conducting a bioblitz using a quadrat where every visible species in a metre square is identified and estimates are made on the prevalence of any individual species.

\section{The Setting}

These woods are approximately 10 acres of mixed deciduous, approximately 300 years old and with a lake. A large chestnut tree dominates the space used by Nature. It is more open at one end so that fields and changes to the crops can be seen and farmers' activities can be heard. It is a lightly managed site and local people do not heavily visit it. 


\section{Methods}

The methods were selected to allow emotional literacy to be assessed quantitatively and well being to be explored qualitatively.

Emotional literacy assessment. The Emotional Literacy Checklist (ELC) (Southampton Psychology Service 2003) was chosen, as it is a well-established measure and one used previously by Nature Workshops. The ELC is designed to assess emotional literacy using five key sub-scales: empathy, motivation, self-awareness, self-regulation and social skills. Each sub-scale is scored on a 4-point scale (very true; somewhat true, not really true, not true at all). The ELC for parents and pupils has 25 items (5 per sub-scale; total possible score 100); the ELC for teachers has 20 items (4 per sub-scale; total possible score 80 ). The teachers and parents answers reflect the statements best describing how the young person usual is; the young person selects the statement best describing how they perceive themselves to be. A higher ELC score indicates better EL. The young person, parent and teacher completed prior to and after the intervention the ELC.

Interviews, poetry and discussions. Interviews were undertaken with the young people's parents and their teachers pre-intervention took place in order to explore how they thought the young people would react and what impacts they thought the activities might have on them. They were also asked about their hopes and aspirations and any concerns about the project. Interviews were also undertaken post-intervention to facilitate re-examination and exploration of these issues.

Rather than undertake interviews with the young people, data were generated with the young people through the discussions that occurred naturally during the course of the project and through the poems that the young people wrote whilst part of the project. Some of these discussions were one-toone, others occurred with the young people in pairs or within the group; these discussions occurred either during the activities or after the sessions.

Data were also generated from the project staff through reflective debriefing sessions and via fieldwork journals in which staff noted issues of importance, the young people's responses and what was working well for individual young people. 


\section{Data analysis}

The quantitative data from the ELC's were analysed using simple descriptive statistics. The interviews, discussions, field notes and poems were transcribed, anonymised and pseudonyms used. These qualitative data were coded using the well-being parameters (psychological, emotional, social, physical and natural connection) and their associated indicators (see Table 2). Each transcript was coded and analysed separately before being considered as part of the entire data set.

Table 2: Well-being parameters and indicators

\begin{tabular}{|l|l|}
\hline Well-being Parameter & Feelings indicative of /associated with parameter \\
\hline Pyschological & - Feelings of being in control \\
& - Feelings of being competent (and seen by others as competent) \\
- Energetic & - Purposeful \\
- Developing oneself & - Connecting with others through shared beliefs and outlook \\
& - Secure with personal limitations \\
\hline Emotional & - Absence of negative emotions and moods \\
& - Feeling even-tempered \\
& - Relaxed \\
& - Optimistic about the present \\
& - Optimistic about the future \\
& - Emotional literacy \\
\hline Social & - Feelings of being confident \\
& - Feelings of being accepted \\
& - Safe and supported within and through social relationships \\
\hline Physical & - Feelings of physical health \\
& - Confidence and enjoyment of physical activity \\
& - Feelings of physical comfort \\
\hline Natural Connection & - Feelings of closeness to the natural world \\
& - Being engaged in a relationship with nature \\
\hline
\end{tabular}

\section{Findings}

\section{Demographics}

Eight young carers, three females and five males aged between 9-13 years took part. The young carers caring activities resulted from parental depression and other mental health problems, drug addiction, managing prescriptions and learning difficulties; one parent was wheelchair bound.

The young people were providing regular, often daily care, for a parent. This included 
providing support to parent dealing with depression, other mental health problems, drug addiction, learning difficulties or with very limited mobility. Their caring roles included providing emotional support, housework, cooking, helping look after siblings and managing prescriptions. One of the girls has learning difficulties and three of the 3 boys had ADHD and behavioural issues at school.

The young carers or their parents selected a teacher to speak with us pre and post intervention, apart from one young carer where a scout leader was the chosen adult.

\section{Emotional Literacy Checklists}

When summing the scores for all items, the cumulative scores for young people show a slight drop 73/100 pre-test to 70/100 post-test, with parents' scores rising from 64/100 to 77/100 and teachers' scores rising from 54/80 to $61 / 80$ pre-test to post-test (see Figure 1). The parents and teachers reported improvements in motivation, self-awareness, self-regulation and social skills although neither group reported improvements in empathy. The results from the young people show drops in all sub-scales apart from motivation that remains static. It is not clear why the young people's scores do not show the same improvement as that scored by their parents and teachers. However, their post-test scores perhaps reflect greater confidence in scoring their 'truer' feelings.

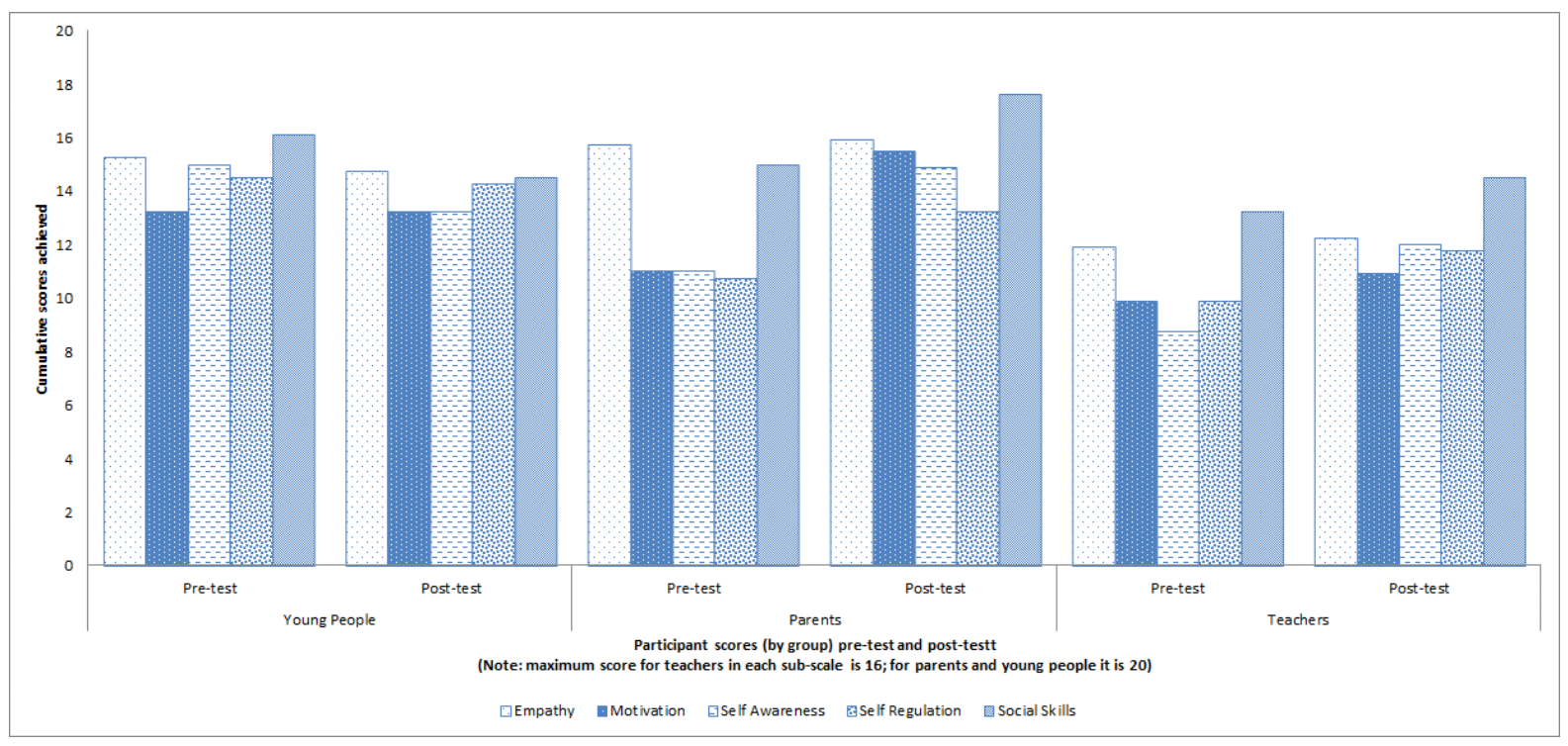

Figure 1: Participant scores (by group) pre-test and post-test 


\section{Well-being}

Although the young people's responses were low in psychological and emotional well being indicators compared to the adults' responses, their responses were higher in physical activities and natural well being in comparison to the adults, although one parent reported an improved awareness of connections between the natural world and behaviour. The well being indicators most frequently mentioned by the young people were 'safe and supported within and through social relationships' (social well-being), 'developing oneself' (psychological well-being) and 'connecting with others through shared beliefs and outlook' (psychological well-being). The use of poetry with the young people provided a useful insight into their children's feelings as this elicited richer data than was generated using more direct, audio-recorded questioning as an approach.

Prior to commencing the project the adults had some clear expectations of the benefits the young people could reap, expecting that they would benefit from "no constraints, no electronics and no television” (Teacher) and that the young person would be:

"given the help and support they need to succeed... and that will in itself, help

boost their confidence and help them come back to school feeling like they can succeed in the next academic year"(Teacher)

There was an expectation that although there would be a certain amount of freedom the young person would not be "left to their own devices" as the intervention would have sufficient structure to facilitate the young person's learning as having "something set up" meant that the young person would "always get something out of it"

The findings from the young people reflected their enjoyment of the sessions and how the intervention had affected their lives.

\section{Social well being}

Feeling 'safe and supported within and through social relationships' was important for the children who often felt uncertain or insecure. A line from one of the young people's poems summed up their feelings when saying:

'Inside me I feel free and ready to find my journey and path'. 
Many expressed of the young people 'feelings of being accepted' and talked of their enjoyment of being together saying "it's fun to meet new people” and being able, to 'support other people' and 'be accepted', for example one of the young people talked about liking to be able "to work together as a team" another was thankful for being “cheer[ed] up when I was upset about my Nan”. They also enjoyed the activities saying that they liked "to do the games". Well being also benefited from being with people who understood them and the sense of 'feeling accepted'. The sense of acceptance learned within the project rippled out beyond the project; one parent described how her daughter had:

"all of a sudden started to find new friends that do different things whereas before

it was all friends on the X box now she's got new friends and going out skating”.

Parents and teachers noted changes in 'feelings of confidence' through the ways in which the young people were more able to sustain social relationships. For example, one teacher explained:

"I think he's a lot happier - he's come back into year 8 with more of a smile on his face"

The parents noted positive changes in their children's social skills such as being more “accepting of people’s ideas” (Parent); these changes were welcomed and reported as being “nice, you know". Staff noted that by the end of project the young people's social well being seemed to be “remarkably different from day one”.

\section{Physical well being}

The young people clearly developed their 'confidence in and enjoyment of physical activity' through their engagement in the outdoors and enjoyed the freedom it engendered such as the chance of "being in mud and boggy places". Through making physical activity enjoyable by using group activities - such as water fights - which would perhaps be discouraged at school or in other places, the children were able to explore boundaries and experience their bodies in a different way.

At the end of each day the children were encouraged to reflect on the 'best bits' and they talked animatedly about the names of the games such as 'hiding', 'bat and moth', and 'sardines' and the fun they had playing these physically active games. 


\section{Natural Connections}

Young people expressed their 'feelings of closeness to the natural world and being engaged in a relationship with nature' in many different ways and enjoyed the opportunities for being in the woods and the taking part in the different activities. Some of their responses were nature were evocative; one young person explained in a poem that "Inside I feel happy to be where nature grows". Their poetry was evocative of connections with the natural world taking notice of the "squelchy mud" below them, the "muddy path reaching out", and as one poet explained: "Above I see tall trees, Below I see my little nest”.

Other young people talked about how "making a fire" was a skill they learned that helped to link them to nature. One of the parents talked of the connection her children now had with the natural world ('engaged in a relationship with nature') explaining:

“... they realized how beautiful it is out there, instead of being stuck in, they've actually realized how lovely woodland places is or just to go to a field with trees. Like Jack will go to a field with a tree with his mates and stuff”

\section{Psychological well being}

The psychological parameter covers feelings of competence, control purpose and connectivity and the parents and teachers saw positive outcomes from the project. One of the main areas was the young people's enhanced ability to 'connect with others through shared beliefs and outlook'. Engagement in activities such as hiding together (sardines) required the young people to share space with others and they developed confidence to enjoy this activity. Some of the parents perceived improvements, for example, one parent explained how her son was now " $a$ little bit more understanding" and another described how her son now seemed to be "a lot more positive"

Along with 'feeling more competent' some of the young people were 'seen as more competent' and were described as being more "self reliant" and able to "work on their own with something natural". One of the parents reported that an improvement in the reliability of their children, explaining that:

“...they are actually starting to clean up after themselves, and they're not 
expecting me, I have to say 'excuse me' but they will do it”

One of the teachers noted how a young person was now "getting more organised" and "getting places on time”.

\section{Emotional well being}

Overall, the data reflected improvements in the young people's emotional well being, often through an absence of getting "into trouble". The young people's poems reflected a sense of happiness with most of them reflecting on "feeling happy inside". One teacher was impressed by the determination and 'sense of purpose' that seemed to result from her pupil's engagement in the programme stating:

"..For me the significant thing this year was the coast to coast walk which he

did...that's still etched in my mind, the determination on his face that he was going to

finish it.... he did it all the way you know... fantastic"

Another teacher noted that that her pupil was had a stronger 'emotional literacy' and fewer 'negative emotions and moods' noting he was “less willing to blame other people for things”.

Another teacher noted evidence of improvements in behaviour through a marked reduction in the number of detentions of a pupil who had been "picking up one detention a week" prior to the project, saying, "he’s doing lovely".

The project had wider implications for some of the young people who developed an 'energetic' and 'purposeful' approach to recycling, even though no mention had been made about recycling during the sessions.

\section{Discussion}

The young people in our study felt that change had happened and they felt more positive and confident about their lives even if this was less evident in their ELC scores. Measuring changes to young people’s well-being and emotional literacy is complex and not easily amenable to scoring. The parents and teachers reported greater improvements in EL than the children themselves. Measurable improvements were noted in motivation, and social skills (parents) and self-awareness (parents and 
teachers); it is possible that the children's growing self-awareness is partly responsible for the reductions in the other parameters measured on the children's own checklists. However, the fact that the children and other stakeholders reported feeling 'safe and supported within and through social relationships' is reflective of improved social skills. Parents in our study noted changes in in 'difficulty in remaining focused on unappealing tasks', 'difficulty in completing tasks, 'difficulty in listening and following directions', and 'difficulty in resisting distractions' and this has resonance with Kuo et al.'s (2004) findings that green outdoor activities undertaken by children $(n=528)$ in the USA reduced symptoms of ADHD significantly more than the other 48 activities on offer. Findings from Sweden show the 'restorative potential' of impact of open green spaces and the fraction of visible of sky on young children's (aged 4-6 years) inattentive, hyperactive and impulsive behaviours. Whilst the age group is different to that of our study the findings have resonance with the shifts in social skills. Work undertaken by Roe and Aspinall (2009) used a similar model of intervention to that used in our study and their urban woodland experience was found to have a positive impact on young people deemed to have poor behaviour.

Somewhat at odds with the lack of improvement in the Emotional Literacy scores, there was evidence of improvements in the children's well-being through their conversations and actions and through the three 'top' well-being indicators - 'safe and supported within and through social relationships', 'developing oneself', 'connecting with others through shared beliefs and outlook'. Considering the nature of the intervention, it is not surprising that the children's comments were more heavily concentrated on physical and nature based elements of well-being. The children's enjoyment of the natural environment and the woodland activities may be both reflective of children's enjoyment of being in nature but also be reflective of their particular enjoyment of being able to escape their caring responsibilities. There is no direct literature to use as a basis for comparison however, work by Korpela and Kytta (2002) among 55 children aged 8-13 years in Finland used a measure of preferences for spending time in a child's 'favourite places' and the impacts on restoration and self regulation and found that preferences were socially motivated. Similar to the improvements noted in our study in relation to 'safe and supported' and 'connecting with others' measures, Waliczek et al.'s (2001) work on the value of school gardens for children (aged 5-13 years) found improvements in 
interpersonal relationships, especially for the older children who had been given permission to work more independently. Follow-up work by Zadicek and Robinson (2003) showed 'positive influences' in 'working with groups' and 'self-understanding'.

The findings from the study show the promise of woodland based work but they are limited by the small sample size, and the specificity of the sample (young carers) and the setting to be able to make global statements about the value and effectiveness of this type of work for future participants.

\section{Conclusions}

The young carers benefited in many ways from participating in the 'Good from the Wood' project. They enjoyed the freedom engendered by being outdoors and being able to undertake physical activities in the woods. They developed friendships and reported feeling happier and were better able to relate to their peers. Their teachers and parents noted that they were more settled and that her behaviour had improved. 'Good from the Wood' provided the young people with a break away from their caring responsibilities. It literally gave them a chance to be carefree; the chance to learn the woods and themselves, to get muddy and to gain confidence. Young carers are at risk from poor mental health outcomes and low well-being, interventions such as 'Good from the Wood' can reduce the risks of these poor outcomes. Many health professionals and nurses who work with children and young people are unaware that children within their clinics and wards may be acting as a carer for their parent. Increased awareness of the health-related issues associated with being a young carer is a fundamental step for children's nurses to take to ensure that they can sensitively and appropriately support young carers. 


\section{References}

The Children's Society. (2014). The Good Childhood Report.

http://www.childrenssociety.org.uk/sites/default/files/The\%20Good\%20Childhood\%20Report\%20 2014\%20-\%20FINAL 0.pdf (Accessed 27 $7^{\text {th }}$ August 2015)

Bradshaw, J. and Richardson, D. (2009). An index of child well-being. Child Indicators Research 2, 319-351. doi: 10.1007/s12187-009-9037-7

Bjorgvinsdottir, K., \& Halldorsdottir, S. (2014). Silent, invisible and unacknowledged: experiences of young caregivers of single parents diagnosed with multiple sclerosis. Scandinavian Journal of Caring Sciences, 28, 38-48. doi:10.1111/scs.12030

Doutre, G., Green, R., \& Knight-Elliott, A. (2013). Listening to the voices of young carers using Interpretative Phenomenological Analysis and a strengths-based perspective. Educational \& Child Psychology, 30, 30-43

Elsley, S., (2004). Children's experience of public space. Childhood and Society, 18, 155 - 164. doi: 10.1002/CHI.822

Faupel, A (ed), (2003). 'Emotional Literacy: assessment and intervention', Southampton Psychology Service, GL Assessment Ltd, London

Fjortoft, I. (2004). Landscape as Playscape: The Effects of Natural Environments on Children's Play and Motor Development. Children, Youth and Environments, 14: 21-44 http://www.jstor.org/stable/10.7721/chilyoutenvi.14.2.0021

Gill, T. (2014). The Benefits of Children's Engagement with Nature: A Systematic Literature Review. Children, Youth \& Environments, 24, 10-34. doi: 10.7721/chilyoutenvi.24.2.0010

Goleman, D. (1996) Emotional Intelligence: Why It Can Matter More Than IQ. Bloomsbury Publishing, London

Good from Wood, XXXX

Hewes, J. (2005) Let the Children Play: nature’s answer to early learning. Early Childhood Learning Knowledge Centre.

http://earlychildhooddevelopment.ca/sites/default/files/u1933/let_the_children_play_natures_answ 
er_to_early_learning_jane_hewes.pdf (Accessed 27th August 2015)

IPSOS MORI/UNICEF (2011) Children's Well-being in UK, Sweden and Spain: The Role of Inequality and Materialism. A Qualitative Study. https://www.ipsos-

mori.com/researchpublications/publications/1441/Childrens-Wellbeing-in-UK-Sweden-andSpain.aspx (Accessed 27th August 2015)

Kaplan, S. (1995). The restorative benefits of nature: Toward an integrative framework. Journal of Environmental Psychology, 15, 169-182 doi: 10.1016/0272-4944(95)90001-2

Korpela, K. M., Hartig, T., Kaiser, F. G., \& Fuhrer, U. (2001). Restorative experience and selfregulation in favorite places. Environment and Behavior, 33, 572-589. doi: $10.1177 / 00139160121973133$

Louv,R. (2010) Last Child in the Woods. Algonquin Books of Chapel Hill, Chapel Hill. ISBN: 9781848877498.

McAndrew, S., Warne, T., Fallon, D., \& Moran, P. (2012). Young, gifted, and caring: A project narrative of young carers, their mental health, and getting them involved in education, research and practice. International Journal of Mental Health Nursing, 21, 12-19. doi:10.1111/j.14470349.2011.00762.x

Pretty J, Peacock J, Hine R, Sellens M, South N, Griffin M. (2007). Green exercise in the UK countryside: Effects on health and psychological well-being, and implications for policy and planning. Journal of Environmental Planning \& Management. 50: 211-231. doi:

$10.1080 / 09640560601156466$

Southampton Psychology Service. (2003). Emotional literacy Checklist: Assessment and intervention. London, UK: nferNelson

Steiner, C. (1997). Emotional Literacy: Intelligence with a Heart: A Personal Program to Increase your Emotional Intelligence. New York: Avon Books

Steiner, C. \& Perry, P. (1997). Achieving Emotional Literacy. London: Bloomsbury

Sutton, P. W., Love, J. G., Bell, J., Christie, E., Mayrhofer, A., Millman, Y., Williams, H., Yuill, C. (2005) The Emotional Well-Being of Young People: A Review of the Literature. Robert Gordon University, Aberdeen 
Weare, K., \& Gray, G. (2003). What Works in Developing Children's Emotional and Social Competence and Wellbeing? Research Report RR456. Dept for Education and Skills. www.education.gov.uk/publications/eOrderingDownload/RR456.doc (Accessed 27th August 2015) 